\title{
Novedades en la web del IAPH
}

Marzo a mayo de 2004

En mayo

> Dossier temático "El Patrimonio Histórico en la España de las Autonomías" (PH 48)

$>$ Fichas descriptivas de los volúmenes de la colección Cuadernos y Cuadernos Técnicos

$>$ Novedades sobre becas y ayudas en el ámbito de la cultura y el patrimonio

> Actualización del apartado "Textos-e" en Información PHA (PH 47, febrero 2004)

> Boletín de Novedades de la Biblioteca (diciembre 2003-abril 2004)

> Boletín de Novedades de la Fototeca (mayo 2004)

En abril

> Estadisticas del Servidor Web correspondientes a marzo de 2004 en el apartado "Sede Web"

> PH Boletín nº 48 (abril 2004)

$>$ Novedades sobre becas y ayudas en el ámbito de la cultura y el patrimonio
En marzo

$>$ Estadísticas del Servidor Web correspondientes a febrero de 2004 en el apartado "Sede Web"

> Novedades sobre becas y ayudas en el ámbito de la cultura y el patrimonio

> Renovación del Calendario de Actividades de Formación en España y otros países

> Actualización de la información de Cifras en el apartado "Sede Web": fechas destacadas en la implantación de otros productos y servicios y datos estadísticos relevantes

> Puesta al día de la lista de correos-e y teléfonos del IAPH

> Estadísticas de los Servicios de Información correspondientes al año 2002.

Susana Limón Rodriguez

Centro de Documentación del IAPH

\section{Continúan los encuentros adscritos al proyecto ANSER}

Entre los días 17 y 18 del pasado mes de abril tuvo lugar en Roma el $2^{\circ}$ Seminario del Proyecto ANSER (Antiguas Rutas Marítimas del Mediterráneo) (sobre la participación del IAPH, véase PH 46, p. 11). En esta ocasión el Seminario estaba dedicado a la temática de Las estructuras de los puertos y fondeaderos antiguos, contando con la participación de grandes especialistas en la materia.

La jornada del 16 de abril estuvo dedicada a presentar el estado de la investigación internacional sobre los antiguos puertos y fondeaderos del Mediterráneo occidental. Tras la inauguración oficial del seminario por parte de un representantes de la Región del Lazio, los representantes enviados por Andalucía, Comunidad Valenciana, Cataluña, Francia, Liguria, Toscana, Marruecos y Malta hicieron un repaso de los últimos hallazgos en cada uno de sus territorios.

Para la jornada del 18 de abril se escogió como sede el Castillo de Julio II en Ostia Anti- ca. En la primera parte de la mañana se presentaron los resultados de las investigaciones arqueológicos y geofísicas efectuadas durante los últimos años en el territorio del antiguo puerto de Ostia, infraestructura maritima mandada a construir y desarrollado principalmente durante el mandato de los emperadores Claudio y Trajano.

En paralelo a la celebración del $2^{\circ}$ Seminario se desarrollaron reuniones del Comité de Dirección del Proyecto ANSER y del Comité Científico al objeto de debatir sobre el desarrollo del mismo y la organización de las actividades formativas que, a partir del mes de mayo se han puesto en marcha en el marco del Proyecto.

Centro de Arqueología Subacuática del IAPH

Área de Difusión

Symposium internacional sobre construcción naval en la Antigüedad

Agosto de 2005. Agia Napa, Chipre

Más información:

www.tropis2005.conferences.gr 